\title{
Meanings of thinness and dysfunctional eating in black South African females: a qualitative study
}

\author{
PF Morris, CP Szabo \\ Division of Psychiatry, Department of Neurosciences, Faculty of Health Sciences, University of the Witwatersrand. South Africa
}

\begin{abstract}
Objective: This study qualitatively explored local meanings of thinness and dysfunctional eating in black adolescent females in the rapidly westernizing socio-cultural context of post-apartheid South Africa. Method: Four ( $\mathrm{n}=4$ ) urban state highschools in KwaZulu-Natal were selected from which 40 subjects were sampled from Grades 9-12. Focus groups were conducted following a semi-structured interview and analysed using Constant Comparative Analysis. Results: Subjects reported a wide range of different meanings for thinness, which included traditional idioms of distress and typically western pressures towards thinness, which was particularly evident in the multicultural schools. Subjects also reported a wide range of dysfunctional eating practices (such as purging) which were underscored by a wide range of motivations, including traditional practices and western body image concern; and which did not tend to follow patterns of 'dieting' that are typical in affluent, western societies. Conclusion: Western pressures towards thinness may be blending with traditional idioms of distress and culturally sanctioned rituals of remedial purging and social over-eating, thereby placing this group at particular risk for a range of dysfunctional eating patterns that may not follow typically western paradigms or diagnostic systems.
\end{abstract}

Keywords: Meanings of thinness; Eating disorders; Non-western, South Africa

Received: $10 / 03 / 2011$

Accepted: 09/1 1/2012

doi: http://dx.doi.org/10.4314/ajpsy.v16i5.45

\section{Introduction}

The use of western criteria for eating disorders has been criticized in non-western populations ${ }^{1}$ such as in black South Africans $^{2}$, due to transcultural differences in the meaning of thinness and dysfunctional eating. Eating disorders ${ }^{3}$ have traditionally been conceptualized as a western culture-bound phenomenon ${ }^{4}$ where the thin body type is idealized as a metaphor of beauty and attractiveness. White women from industrialized western countries have thus been seen as particularly at risk for the development of eating disorders, while black and non-western women have been thought to be protected by contrasting ideals which value plumpness as a metaphor of attractiveness, fertility and prosperity, ${ }^{5,6}$ The construct of eating disorders was thus formulated within a western frame of reference and the presence of body weight/image concern is seen as a cardinal diagnostic

\section{Correspondence}

Prof. CP Szabo

Division of Psychiatry, Faculty of Health Sciences, University of the

Witwatersrand. 7 York Rd, Parktown, 2193, Johannesburg, South Africa

email: Christopher.Szabo@wits.ac.za symptom. Generalist perspectives, however, highlight the pathoplasticity of eating disorders where subjective attributions regarding food refusal may vary according to local culture and context. ${ }^{1}$ Research has, indeed,

demonstrated that in non-western countries where thinness is not valued, anorexia nervosa has not been accompanied by weight concerns, but by other, more culturally relevant complaints. ${ }^{7}$

An accumulating body of evidence has also indicated that meanings of thinness and food refusal may not only vary from culture to culture, but may vary even within western culture, such that thinness and self-starvation have expressed a plurality of different meanings across history ${ }^{8}$ and different contexts. Thinness and food refusal have, for example, been seen as an idiom of personal distress ${ }^{9}$ and protest ${ }^{10}$ as well as a symbol of power, control, autonomy, achievement, success, social acceptance and self-value ${ }^{11}$ across different contexts. Di Nicola ${ }^{12}$ noted the changing face of anorexia which he described as "anorexia multiforme"- a "historical chameleon" ( $\mathrm{p}$ l) that changes with the times.

Research has also demonstrated a range of different meanings and motivations for thinness amongst non-western 
communities. Pike and Borovoy ${ }^{13}$ found that Japanese meanings for thinness were more about delaying maturation within the social context of the time, than about ideals of beauty and attractiveness. Becker ${ }^{14}$ also found that the shift towards thinness in westernizing Fijian young women was more about economic and social competition where young women identified with media role models of success in modern, consumeristic lifestyles. Similarly, Katzman, Hermans, Van Hoeken, and Hoek ${ }^{15}$ concluded that Caribbean women may have used thniness as a means of constructing a coherent sense of identity in a period of rapid social change where women were 'caught between' traditional and modern worlds. Anorexia has thus been proposed as a syndrome of culture-change in communities that are undergoing rapid social, economic or cultural transformation, where women may attempt to navigate changing cultural referents using the concrete and explicit medium of the body. ${ }^{16}$ Le Grange, Louw, Breen and Katzman ${ }^{2}$ highlighted that typically western meanings and eating behaviors may not be pertinent in non-western and developing countries such as South Africa where many young black females still live in economically deprived circumstances. These authors found that motivations for dysfunctional eating attitudes and behaviors reflected inadequate food resources rather than western dietary restriction and that typically western, forms of dieting may not be affordable in this community. Affirmative responses to items on purging were also explained in terms of cultural rituals of purging rather than typically western issues of body image and weight.

Lester ${ }^{17}$ argued that definitions which require the presence of body image concern as a cardinal symptom of eating disorder may simply endorse existing epistomoligies by engaging eating disorder and western culture in a "kind of circular reasoning" where they are "posited as both evidence and explanations for one another" (p 609). Lee cautioned that research which uses typically western definitions of eating disorder may marginalize these atypical forms of eating disorder and limit our understanding of these disorders. Lee ${ }^{1}$ and Lester ${ }^{17}$ thus argued the need for ethnographic research which seeks to understand local meanings and language around thinness and dysfunctional eating and to take these factors into account in the execution as well as the interpretation of research.

During the years of apartheid, black and white South Africans were kept apart by the policy of apartheid which encouraged the polarization of distinct ethno-cultural groups based on racial characteristics. Following the dissolution of apartheid in 1994, South Africans of all racial and cultural groups have been able to associate freely thus sharing cultural ideals and practices, such that many ethnically traditional, black, South African females are now being exposed to western ideals and pressures towards thinness. This was seen as an internationally unique opportunity to capture society in the process of westernization and identify meanings of thinness across contexts with differing potential for westernization. The current study thus attempted to explore local meanings of thinness and dysfunctional eating in the rapidly westernizing socio-cutural context of black adolescent females in post-apartheid South Africa.

\section{Method \\ Sample}

The province of KwaZulu-Natal was selected as the location for the study as most black schoolgirls in this province are of Zulu cultural origin i.,e. there is relative homogeneity. Five ( $N=5)$ state-assisted, urban, high schools (Schools A-E) were selected with a view to provide a cross-sectional sample of schools with differential degrees of ethno-cultural integration and potential contact with western ideals of thinness. Focus groups were conducted with 40 black female subjects from 4 of these schools which represented decreasing black-majority status, namely School A=100\% black students in an historically, allblack, low-income, urban township; School B=96\% black majority students in a formerly 'whites only', westerndominated school in a middle income area; and Schools D=39\% and $\mathrm{E}=13 \%$ black minority, in western-dominated schools in formerly 'all-white', economically privileged, areas. Subjects were sampled from Grade 9 (14years) to Grade 12 (18 years).

All black female learners in Grades 9-12 (14-18 years) at Schools A, B, D and E were given consent forms for the Focus group ( $\mathrm{N}=652$ consent forms distributed). Only 40 of these learners returned affirmative parental and individual consents and were all accepted to participate in the groups that were held at each school (School A=10 participants; School B=13; School D= 8; School E=9).

\section{Focus Groups}

These were conducted to explore local meanings of thinness and dysfunctional eating and to evaluate the trans-cultural validity of western diagnostic constructs. Subjects were asked their views on eating disorders following a semi-structured interview that progressed from open-ended questions such as "Do you know of anyone in your school who is too thin? Why do you think they are too thin?" to more specific questions such as "Do you know of any girls in your school who don't eat enough even when there is sufficient food available? Why do you think they do this?" - to more specific questions such as "Do you know of any girls who are unhappy with their body weight and wish they were thinner? Why do you think they want to be thinner?" and "Do you know of any girls who avoid eating / vomit / take laxatives to control their weight". A Zulu-speaking research assistant was present at all times and the Focus group at School A was conducted in Zulu, using the assistant as interpreter. Groups at the other schools were conducted in English. Audiotapes of the groups were analyzed using Constant Comparative Analysis. ${ }^{18}$

\section{Ethics}

Formal approval for the study was obtained by the Human Research Ethics Committee, University of the Witwatersrand and the study was conducted in accordance with their principles and protocols.

\section{Results}

\section{Experience of Eating Disorders}

There was widespread resistance amongst parents to sign consent for their daughters to join the groups. Investigation revealed that they were angry that a 'white woman' was coming to talk to their daughters about a 'white women's disorder'. The girls were, however, keen and many tried to join the group without parental consent. All groups knew of a few black learners 
in their schools who were 'too thin' but generally agreed that many more white girls are too thin: "They are mostly thin". Most participants did not think that eating disorders were a problem in the black community and only one black learner, at School E, was identified as suffering from anorexia nervosa. One participant disclosed that she had been treated for severe weight loss when she first arrived in South Africa as an immigrant from a FrenchCongolese background.

\section{Meanings of Thinness}

All schools spontaneously placed physical factors and stress as primary reasons for 'getting too thin'. Schools A and B focused on these factors which included illness such as AIDS and tuberculosis, drug abuse, inadequate food resources (although this was thought to be extremely rare) and stress due to family and financial problems, sexual, emotional or physical abuse and social difficulties. Girls were seen as more sensitive to stress than boys: "Girls carry their stress- (they) tend to keep quiet and hold it in - it makes them thin". Participants at School B made a distinction between these forms of thinness as "sick skinny" (too thin) and "nice skinny" which was seen as "trendy". Only School D spontaneously offered body dissatisfaction as a reason for 'getting too thin' and this was seen as a problem only in "those (girls) who are caught up in modeling and appearance". No participants spontaneously offered 'dieting' as a reason for becoming 'too thin'.

\section{Pressures towards thinness}

More direct questions revealed widespread, typically western, desire for thinness and pressure from media and role models such as Naomi Campbell who were given as examples of 'nice skinny' "Skinny is beautiful" - "fashionable". Pressure to be thin was also experienced from clothes sizes where all the "trendy clothes are only available in small sizes". They also acknowledged pressure to be thin in order to attract a boy-friend: " all the popular girls are skinny"; "Boys think they are hot". All groups also described negative pressure such as teasing from peers, boys and family members if they if they gain body fat, such as during puberty. One participant had been named 'Fat Attack' after a diet product.

Schools D and E noted that comparison with white peers was a source of pressure and described thinness as a means towards social acceptance and self esteem: "White girls are obsessed about their weight and we spend a lot of time with them, so we start comparing ourselves to them and that is where the pressure is coming from. We think if SHE is fat, then what am I? They described how this pressure was "drummed into" them so much that they became hyperconscious of their weight and shape, and spent a lot of time body-checking: "We are very sensitive about our weight. When I look in the mirror, I just see fat. You try to push it (the pressure) away-but eventually it gets to you. You have to look a certain look. If you don't- there is something wrong with you. If you are fat you, you feel like you are useless. You have to be someone you are not, just to please others and be accepted".

Multicultural schools also identified stress due to conflicting cultural expectations (acculturative stress) and cultural identity confusion: "We don't know who we are because we are split between white and black...like its two totally different cultures... like you can't mix them...you can't become one person because you have to be one thing at home and another at schoolso then you end up not knowing your identity"; " Its confusing.... you are sort like what am I?- and you just can't seem to adjust to it'.
They also described thinness as a means to construct a more coherent sense of identity: "People comment so much on your weight that weight becomes YOU- people judge you not for who you are but what you look like, (so) you stop becoming a person (and) wherever you go, people just see your weight. You, you lose your identity - your identity becomes that- you lose your identity to your body- it becomes everything. Then, when you lose weight, everyone compliments you - so you feel better about yourself- and you want to lose more weight".

\section{Dysfunctional Eating Behaviors}

Skipping meals was acknowledged as a common practice across schools and was largely attributed to stress: "İts too stressful in the mornings to eat breakfast'. Skipping meals was also attributed to feeling embarrassed to eat food brought from home, at school: "We eat different food from white people, like cabbage - and phutu (traditional maize) - and stuff. It's not IN to eat food like that İts embarrassing when white girls ask us what we eat at home or when we bring, bring food from home- some girls throw that awaythey just don't eat at school'. More direct questioning revealed that skipping meals was also a common form of weight control across schools: "We all watch what we eat. It's difficult to eat at school because everyone judges what you eat". Participants were also aware of girls who tried to lose weight by other means such as smoking, drug use, diet pills, drinking vinegar, fasting, exercising, purging (vomiting), drinking hot water before eating and using herbal laxative preparations. All schools acknowledged use of purging (vomiting) as a means of weight control, while only a few participants at Schools D and E acknowledged dieting, by altering the quality of dietary intake or using 'diet' products, as a form of weight control/loss.

All groups noted that in the Zulu culture, purging is traditionally seen as a necessary form of 'cleansing' to promote wellbeing and as a remedy for a wide range of physical and emotional maladies. They reported that many, traditional, black people drink water and induce vomiting, daily, before eating breakfast: "Like you drink your coffee, they (many black people) drink water and vomit in the morning". A participant at School A spontaneously disclosed that she practised this morning vomiting as a cultural routine, but on more direct questioning, admitted that she vomited after eating breakfast, rather than before, which is customary. Regular purging with laxatives was also identified as a traditional practice and all girls acknowledged that they had been forced to have regular purging with laxatives when younger. They reported that their mothers bought boxes of laxatives along with the family grocery shopping: "They (the family) use them (laxatives) all the time. More than you are supposed to. My mom buys a lot (of laxatives), because she says that when we eat too much sugar or other unhealthy things - she says that we must take laxatives to get rid of all the toxins or whatever."

All groups were aware of girls who engaged in binge-eating, particularly a pattern of fasting all day at school, then bingeeating or over-eating in the evening at home. They also noted that it is customary to eat large quantities of food at social gatherings and that they are pressurized to eat copious amounts of food, particularly traditional foods, which can be fattening. Some participants admitted that they induce vomiting after these meals; for some, this was used as a means of weight control; while others noted that their stomachs were not used to eating these traditionally large amounts of food and that that they suffered gastric discomfort, which was relieved by vomiting. 


\section{Discussion}

Analysis of the Focus groups suggested that thinness may be a traditional idiom of physical and psychological distress in this black South African community. This is consistent with meanings of body weight and shape in non-western ${ }^{6}$ and black ${ }^{19}$ women, and with local Zulu custom which has traditionally valued plumpness as a sign of wellbeing; while thinness has been associated with illness, stress or deprivation. Traditional rituals of purging (vomiting and laxative use) were also identified as culturally sanctioned forms of remediation for a wide range of physical and psychological maladies. This is consistent with other research in this community which has indicated the use of cultural purging as a means of 'cleansing' or 'detoxification'. ' Dysfunctional eating practices in this community may thus be underscored by a wide range of different emotional or social stressors which may be expressed in terms of prevailing cultural idioms of distress and remediated by traditional rituals of purging. These findings suggest the presence of atypical forms of eating dysfunction which could represent a wide range of different subjective motivations and attributions; which may not include body image concern.

Typically western meanings of thinness were also identified and there was evidence of widespread media pressure toward thinness and body image concern. Social comparison with white peers exacerbated these pressures in the multicultural schools where failure to attain an ideal weight resulted in body dissatisfaction and feelings of worthlessness; while thinness was seen as a solution for social acceptance and self-esteem and as a means of constructing a coherent sense of identity. This is consistent with research which has found that social comparison with white peers may promote body dissatisfaction amongst nonwestern schoolgirl ${ }^{20}$ who may overcorrect ${ }^{21}$ their body shape in order to be accepted by their western peers. Research ${ }^{14,15}$ has also suggested that women may use the body as a vehicle for the expression of identity, particularly during times of rapid social change when they may need to redefine themselves. ${ }^{16,22}$ Black, South African schoolgirls may thus be particularly at risk for the development of body dissatisfaction and dysfunctional eating attitudes and behaviors, during the period of ethno-cultural integration and rapid socio-cultural transition that is occurring in post-apartheid South Africa.

Evidence of widespread body dissatisfaction did not, however, appear to translate to an increased incidence of anorexia nervosa. Indeed, only School D spontaneously offered body dissatisfaction as a reason for 'getting too thin' and none of the schools spontaneously offered 'dieting' as a reason for 'getting too thin'; although all schools admitted that they knew of girls who tried to lose weight by skipping meals (fasting), exercising and purging (vomiting or laxative use). One participant disclosed that she practiced 'traditional purging' after eating breakfast, rather than before, which is customary; suggesting that she may have been using this form of purging as a means of weight control. Traditional forms of purging could, therefore, also provide a culturally sanctioned remedy for western body image concern/distress, thereby placing these girls at particular risk for purging forms of weight control and eating dysfunction which may not be recognized as eating disordered by the local community. Culturally sanctioned purging may also be easily used as a means of weight control in a subject who does not suffer sufficient body image concern to qualify for anorexia nervosa on typically western diagnostic systems. This resonates with other research which has found that the incidence of typically western anorexia nervosa may be limited amongst African-American women ${ }^{23}$ and that African-American women are more likely to use risky weight loss strategies than white women. ${ }^{24}$ Le Grange et al., speculated that 'typically western' forms of dieting, such as 'counting calories' may not be affordable in economically deprived South African groups, suggesting that fasting and purging may be more common forms of weight control within the economically developing context of post-apartheid South Africa. ${ }^{2}$ Several girls from School A (located in an economically disadvantaged area) acknowledged use of these forms of weight control while subjects at Schools D and E (located in economically privileged areas) noted that purging was not as efficient for weight reduction as dieting by moderating the quality of dietary intake; suggesting that unhealthy weightcontrol practices such as fasting or purging may indeed be more common amoungst economically less privileged communities who cannot afford expensive 'diet' foods. Story, French, Resnick and Blum also found that females from a higher socio-economic status (SES) were less likely than lower SES females, to engage in unhealthy weight control practices, which may be less effective for weight loss than 'healthier' forms of dieting. ${ }^{25}$ Many black South African females may thus demonstrate an atypical, purging form of eating disorder ${ }^{26}$ that fails to qualify for anorexia nervosa in terms of weight criteria or body image concerns; yet requires clinical identification and remediation.

Skipping meals and fasting at school, was also reported as common practise, for a variety of reasons, including cultural differences in food and western pressures towards thinness: and was frequently followed by binge-eating at night. Culturally sanctioned purging could also be easily used as compensatory behavior following episodes of binge-eating and contribute towards the development of bulimia nervosa in this group.

Participants also reported traditional social pressures to overeat, particularly at family gatherings, which resulted in bloating, which was often relieved by vomiting. Bulimia nervosa may also be preceded by overeating or binge-eating ${ }^{27}$, suggesting that culturally sanctioned overeating and purging may also place this community at particular risk for the development of a binge-purge pattern that may not necessarily be accompanied by western body image concerns. Other research has indeed found high levels of binge-eating and purging amongst African-American women 28,29; and bulimic symptoms have been identified in 10\% of black South African females although this particular study did raise the issue of screening instrument validity in the population studied. ${ }^{30} \mathrm{Keel}$ and Klump found that the prevalence of bulimia nervosa across cultures was more sensitive to westernization than anorexia as the specific combination of binge-eating and purging required access to large quantities of food within a social context that motivates for weight control. ${ }^{9}$ Westernizing, upwardly mobile, black South African schoolgirls may thus be at particular risk for the development of bulimia nervosa.

Focus groups thus suggested that black school-girls in South Africa, may be particularly at risk for a variety of dysfunctional eating behaviors which may not be captured by western diagnostic criteria, yet require clinical remediation and prevention. Strong 'opposition' by parents encountered by the researcher, also suggested that these dysfunctional practices may not be recognized as clinically relevant by the community and that many of our young, black schoolgirls may not be receiving the assistance that they need. 


\section{Conclusion}

Findings of the current study suggest that thinness and eating dysfunction may be underscored by a wide range of different meanings and motivations in this black adolescent South African community; including typically western ideals of thinness and body image concern, which were particularly evident in the more westernized, multicultural school contexts. This suggests the presence of atypical forms of eating dysfunction which may not be accompanied by western body image concerns and endorses the generalist perspective that western body image ideals may be the 'social colouring of distress rather than the cause'. ${ }^{31}$

Western pressures for thinness may also be blending imperceptibly with traditional idioms of distress (thinness) and culturally sanctioned forms of remediation (purging), thereby placing these girls at particular risk for the development of purging forms of weight control which may not be captured by western criteria for anorexia nervosa. Culturally-sanctioned overeating and purging may also place this community at particular risk for purging which may not follow typically western patterns or paradigms and may not be captured by western criteria for bulimia nervosa.

Future research is needed to examine the reliability and validity of western diagnostic systems, and identify any atypical forms of eating dysfunction that may exist, within this westernizing and economically developing South African community.

\section{References}

1. Lee S. Engaging Culture: An overdue task for eating disorders research. Culture Medicine and Psychiatry 2004; 24 (4) 617-621.

2. Le Grange D, Louw J, Breen A, Katzman M. The meaning of 'selfstarvation' in impoverished black adolescents in South Africa. Culture Medicine and Psychiatry 2004; 24 (4) 439-461.

3. American Psychiatric Association (APA). Diagnostic and Statistical Manual of Mental Disorders, 4th Edition, Revised: Washington D. C., 1994.

4. Prince R. The Concept of Culture-bound Syndromes. Anorexia Nervosa and Brain-Fag. Social Science and Medicine 1985; 21 (2) 197-203.

5. Kumanyika SK, Wilson JF, Guilford-Davenport M. Weight related attitudes and behaviors of black women. Journal American Dietetic Association 1993; 93, 416-422.

6. Nasser MA. Comparative Study of the Prevalence of Anorexia Nervosa and abnormal eating attitudes among Arab female students of both London and Cairo Universities. Psychological Medicine 1986; 16 (3) 621-625.

7. Lee S, Kwok K, Liau C, Leung T. Screening Chinese Patients with Eating Disorders Using the Eating Attitudes test in Hong Kong, 2002. Publised online in Wiley InterScience (www.interscience. wiley.com).

8. Keel PK, Klump KL. Are Eating Disorders Culture-Bound Syndromes? Implications for conceptualizing their etiology. Psychological Bulletin 2003; 129 (5) 747-769.

9. Katzman MA, Lee S. Beyond Body Image: Integration of feminist and transcultural theories in the understanding of self starvation. International Journal of Eating Disorders 1997; 22 (4) 385-394.

10. Brumberg JJ. Fasting Girls: the emergence of Anorexia Nervosa as a modern disease. Cambridge, Harvard University Press, 1988.

11. Bruch H. The Golden Cage: the enigma of Anorexia Nervosa. Cambridge: Harvard University Press, 1978.

12. Di Nicola V.F. Anorexia multiforme: Self starvation in historical and cultural context. Part 1: Self-starvation as a historical chameleon. Transcultural Psychiatric Research Review 1990; 27, 165-196.
13. Pike KM, Borovoy A.The Rise of eating Disorders in Japan: Issues of culture and limitations of the model of westernization. Culture Medicine and Psychiatry 2004, 24 (4) 493-531.

14. Becker A. Television Disordered Eating and Young Women in Fiji: Negotiating Body Image and Identity during Rapid Social Change. Culture, Medicine and Psychiatry 2004; 28, 533-559.

15. Katzman MA, Hermans KME, Van Hoeken D, Hoek HW. Not your "typical island woman": Anorexia Nervosa is reported only in subcultures in Curacao. Culture Medicine and Psychiatry 2004, 24 (4) 463-492.

16. Nasser M, Di Nicola V. Changing bodies, changing cultures: An intercultural dialogue on the body as the final frontier. In M. Nasser, M.A. Katzman \& R.A Gordon, (Eds). Eating Disorders and Cultures in Transition. East Sussex: Brunner-Routledge, 2001; 171-187.

17. Lester R. Commentary: Eating Disorders and the problem of "culture" in acculturation. Culture Medicine and Psychiatry, 2004; 24 (4) 607-615.

18. Glaser BG, Strauss A. The Discovery of Grounded Theory: Strategies for Qualitative Research. Chicago: Aldine, 1979.

19. Rucker CE, Cash TF. Body Imagess, body-size perceptions and eating behaviors among African-American and white college women. International Journal of Eating Disorders 1992; 12 (3) 291-299.

20. Tsai G, Curbow B, Heinberg L. Sociocultural and developmental influences on body dissatisfaction and disordered eating attitudes and behaviors of Asian women. Journal of Nervous Mental Disorders 2003; 191 (5) 309-318.

21. Davis C, Katzman MA. Perfection as Acculturation: Psychological correlates of eating problems in Chinese male and female students living in the United States. International Journal of Eating Disorders 1999; 25, 65-70.

22. Skarderud F, Nasser M. (Re) figuring identities: My body is what I am. In, M Nasser, K Baistow \& J Treasure (Eds). The Female Body in Mind: The Interface between the Female Body and Mental Health. London: Routledge, 2007, 19-27.

23. Striegel-Moore RH, Dohm FA, Kraemer HC, Taylor CB, Daniels SR, Crawford PB, et al. Eating Disorders in White and Black women. The American Journal of Psychiatry 2003; 160, 1326-1331.

24. Biener AE, Heaton A. Women dieters of normal weight: Their motives goals, and risks. American Journal of Public Health 1995; 85 (5) 714717.

25. Story M, French SA, Resnick MD, Blum RW. International Journal of Eating Diosrders 1995; 18 (2) 173-179.

26. Keel PK, Striegel-Moore RH. The validity and clinical utility of purging disorder. International Journal of Eating Disorders 2009; 42 (8) 706-719.

27. Brewerton TD, Dansky BS, Kilpatrick DG, O'Neil PM. Which Comes First in the Pathnogenesis of Bulimia Nervosa: Dieting or Bingeing? International Journal of Eating Disorders 2000; 28, 259-264.

28. Smith JE, Krejci J. Minorities join the minority: Eating disturbances among Hispanic and Native-American Youth. International Journal of Eating Disorders 1991; 9, 179-186.

29. Pumariega AJ, Gustavson CR, Gustavson JC, Stone Motes P, Ayers S. Eating Attitudes in African-American women: The Essence Eating Disorder Survey, Eating Disorders 1994; 2, 5-16.

30. Edwards D, Moldan S. Bulimic pathology in black students in South Africa: Some unexpected findings. South African Journal of Psychology 2004; 34 (2) 191-203.

31. Russell GFM, Treasure J. The modern history of Anorexia nervosa: An interpretation of why the illness has changed. In L Schneider, SJ Cooper, KA Halmi (Eds). The Psychobiology of Human Eating Disorders: Preclinical and Clinical perspectives. New York: The New York Academy of Science, 1989; 251-271. 